\title{
Nanotopography-Induced Structural Anisotropy and Sarcomere Development in Human Cardiomyocytes Derived from Induced Pluripotent Stem Cells
}

\author{
Daniel Carson ${ }^{\dagger, \ddagger}$, Marketa Hnilova $^{\dagger, \S}$, Xiulan Yang ${ }^{\perp, \Delta}$, Cameron L. Nemeth ${ }^{\ddagger}$, Jonathan H. $_{\text {. }}$ \\ Tsui ${ }^{\ddagger}$, Alec S.T. Smith ${ }^{\ddagger}$, Alex Jiao $\ddagger$, Michael Regnier ${ }^{\ddagger}, \|, \Delta$, Charles E. Murry ${ }^{\ddagger, \perp, \|, \Delta}$, Candan \\ Tamerler§,\#, and Deok-Ho Kim ${ }^{*}$,,$\|, \Delta$ \\ FDepartment of Bioengineering, University of Washington, Seattle, Washington 98195, United \\ States \\ $\S$ Department of Materials Science and Engineering, University of Washington, Seattle, \\ Washington 98195, United States \\ ${ }^{\perp}$ Department of Pathology, University of Washington, Seattle, Washington 98195, United States \\ \#Department of Mechanical Engineering and Bioengineering Research Center, University of \\ Kansas, Lawrence, Kansas 66045, United States \\ "Center for Cardiovascular Biology, University of Washington, Seattle, Washington 98109, United \\ States \\ $\triangle$ Institute for Stem Cell and Regenerative Medicine, University of Washington, Seattle, \\ Washington 98109, United States
}

\section{Abstract}

Understanding the phenotypic development of human induced pluripotent stem cell-derived cardiomyocytes (hiPSC-CMs) is a prerequisite to advancing regenerative cardiac therapy, disease modeling, and drug screening applications. Lack of consistent hiPSC-CM in vitro data can be largely attributed to the inability of conventional culture methods to mimic the structural, biochemical, and mechanical aspects of the myocardial niche accurately. Here, we present a nanogrid culture array comprised of nanogrooved topographies, with groove widths ranging from 350 to $2000 \mathrm{~nm}$, to study the effect of different nanoscale structures on the structural development of hiPSC-CMs in vitro. Nanotopographies were designed to have a biomimetic interface, based on observations of the oriented myocardial extracellular matrix (ECM) fibers found in vivo.

Nanotopographic substrates were integrated with a self-assembling chimeric peptide containing

\footnotetext{
*Corresponding Author: deokho@uw.edu. Phone: 1-206-616-1133. Fax: 1-206-685-3300.

$\dagger$ Author Contributions

D.C. and M.H. contributed equally.

Supporting Information

The Supporting Information is available free of charge on the ACS Publications website at DOI: 10.1021/acsami.5b11671.

Schematic describing the biotin biding assay, table listing the peptide library used for screening, table of the designed and synthesized peptides used in the study, and figure demonstrating the sequence and purity analysis of the designed peptides (PDF)

Notes

The authors declare the following competing financial interest(s): D.H. Kim is a co-founder and scientific board member of a start-up company, NanoSurface Biomedical, that aims to commercialize nanopatterned polymeric cultureware.
} 
the Arg-Gly-Asp (RGD) cell adhesion motif. Using this platform, cell adhesion to peptide-coated substrates was found to be comparable to that of conventional fibronectin-coated surfaces.

Cardiomyocyte organization and structural development were found to be dependent on the nanotopographical feature size in a biphasic manner, with improved development achieved on grooves in the $700-1000 \mathrm{~nm}$ range. These findings highlight the capability of surface-

functionalized, bioinspired substrates to influence cardiomyocyte development, and the capacity for such platforms to serve as a versatile assay for investigating the role of topographical guidance cues on cell behavior. Such substrates could potentially create more physiologically relevant in vitro cardiac tissues for future drug screening and disease modeling studies.

\section{Graphical abstract}

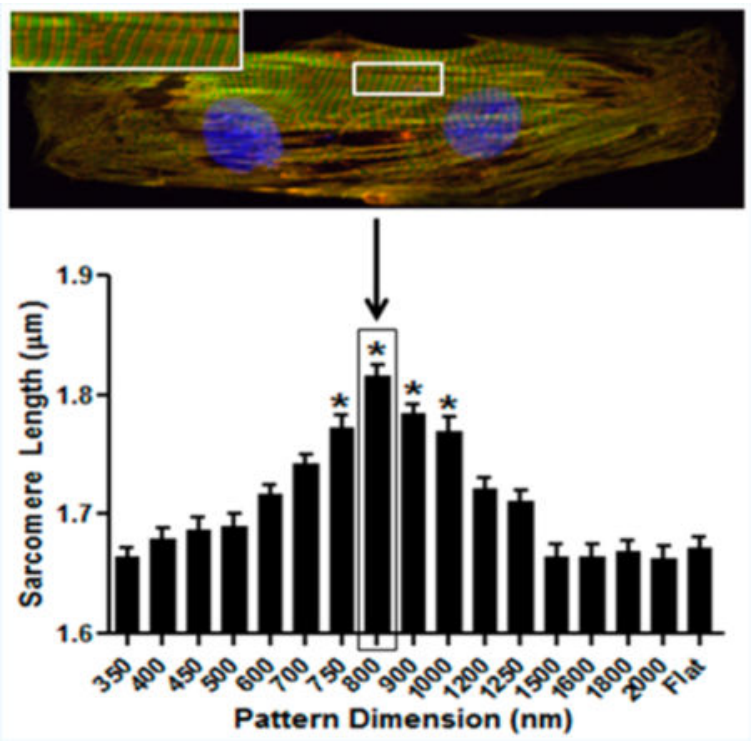

\section{Keywords}

nanotopography; cardiomyocytes; chimeric self-assembling peptide; biomimetic surface; human induced pluripotent stem cells

\section{INTRODUCTION}

Human induced pluripotent stem cell-derived cardiomyocytes (hiPSC-CMs) hold great potential for the development of physiologically relevant in vitro models of myocardial tissue for improving preclinical drug screening, disease modeling, and mechanistic studies of cardiac development. ${ }^{1-4}$ However, a technical limitation in the application of these hiPSC-derived cardiac cultures is that the cardiomyocytes are phenotypically immature compared to those present in the adult heart. ${ }^{5}$ Immature structural, metabolic, and/or functional phenotypes reduce the effectiveness of stem cell-derived cardiac technologies because the engineered tissue is a poor representation of the mature myocardium. ${ }^{6}$ Therefore, improved maturation of hiPSC-CMs in vitro toward more adultlike phenotypes is crucial for the advancement of the field. 
To address this issue, bioengineers have investigated the integration of hiPSC-CMs with numerous techniques for recreating single or multiple characteristics of the native cardiac niche in vitro. ${ }^{7-10}$ The structure of the heart is organized on multiple scales to help promote effective blood ejection from the ventricles and direct the collective movement of action potentials along the tissue to provide strong synchronous contractions. ${ }^{11}$ Tissue alignment is apparent on all levels, from the three-dimensional ultrastructure of the cardiac tissue down to micron-scale sarcomeres within individual cells. ${ }^{12,13}$ To induce similar physiological cellular organization in vitro, we can use topographic cues to manipulate such responses. ${ }^{14}$ This is illustrated by visible and consistent cellular alignment along a common axis and morphological elongation in a manner that is conducive to cellular processes such as migration and differentiation. ${ }^{15,16}$ Furthermore, different types of topographies, such as aligned grooves and pillars, have been used to regulate cell morphology and the development of anisotropic conduction patterns. ${ }^{17-19}$ In the case of cardiac muscle, it has been shown that an underlying nanoscale topography which mimics the dimensions and orientation of the cardiac extracellular matrix (ECM) is capable of promoting the anisotropic orientation of cultured rodent cardiomyocytes. ${ }^{15}$ The use of biomimetic topographies capable of orienting cells in this manner helps drive the development of cellular structure and function in engineered cardiac tissues. ${ }^{15,20}$ However, optimal dimensions for nanoscale topographies in terms of promoting stem cell derived cardiomyocyte development have yet to be established. Furthermore, the capacity for human-derived cardiac cells to respond to exogenous structural cues in a manner similar to that observed in rodent cells has yet to be demonstrated.

In addition to exogenous mechanical cues, ECM signaling is known to be a potent regulator of cellular activity, stimulating or inhibiting pathways that promote proliferation, migration, and/or differentiation. ${ }^{21-23}$ Cellular adhesion to the ECM is largely mediated by a family of membrane-bound proteins named integrins. ${ }^{24}$ Commonly expressed within fibers of the ECM is a three peptide sequence, Arg-Gly-Asp (RGD), that is well-known for its ability to promote integrin-mediated cellular adhesion. ${ }^{25}$ In the case of the myocardium, RGD is found in repeating segments of fibronectin, which facilitates cell-matrix binding through the activity of the $a 5 \beta 1$ integrin complex. ${ }^{26}$

Biopolymers, such as fibronectin, laminin, and collagen, ${ }^{27}$ are often used to coat culture surfaces in order to improve cellular adhesion and development, and such methods have been shown to offer a reliable means of ensuring cell attachment. However, the cost of isolating and purifying human polymers, such as fibronectin, is extremely expensive. Synthetic polymers offer a cost-effective alternative to natural biopolymers, but those used for nanofabrication are often limited by their lack of physiological properties in biological settings, which provides a less than ideal environment for cell culture. In order to address this issue, many laboratories functionalize polymers with biological motifs that facilitate a cell-friendly environment. In such cases, 1-ethyl-3-(3 dimethylaminopropyl)-carbodiimide (EDC) chemistry is often used to covalently link polymeric and biological molecules together. ${ }^{28}$ Although previous groups have demonstrated some success in binding biologically relevant peptides or proteins to synthetic polymers, ${ }^{29-31}$ the process is limited by chemical cross-linking reagents and suboptimal reaction environments. In addition, conjugation chemistry results in poor yields, and does not provide strict control over surface 
distribution of the biological molecule. This lack of definition in the culture substrate, in terms of thickness of the deposition layer, variable coverage, and nonuniform presentation of cell binding antigens, introduces a level of variability into culture surfaces prepared with these peptides. The development of a fully defined culture substrate, with uniform presentation of cell binding motifs, would therefore be beneficial to investigators seeking to generate more reproducible and cost-effective culture environments for subsequent cell culture studies.

Over the past decade, solid binding peptides have been utilized increasingly as biomolecular surface functionalization agents due to their selectivity and high affinity to the materials. These peptides have demonstrated specific and versatile biomolecular recognition-based self-assembly on a variety of inorganic materials such as metals, metal oxides, ceramics, ${ }^{32-36}$ as well as on polymeric materials. ${ }^{37-40}$ The biological nature of these short peptide sequences allows for the incorporation of additional functionalities, thereby providing a means for chimeric protein or peptide design. ${ }^{33,41}$ The combination of the complex functionalities presented in one chimeric peptidic molecule enables adaptable surface functionalization by facilitating the formation of biomimetic interfaces where bioactive domains can be displayed with the desired orientation while building upon the selfassembly of the surface recognition domain. The self-organization of such biomolecular assemblies on surfaces of varying compositions and topographical complexities under physiological conditions make them highly desirable by eliminating the need for complex chemical reactions and harsh chemicals used in conventional chemical cross-linking systems.

Here we report the development of a nanotopographic cell culture platform composed of a 4 $\times 4$-island nanopatterned substrate engineered to have a biomimetic interface for screening hiPSC-CM structural development. The interface is achieved by using a chimeric peptide, which self-assembles onto nanopatterned substrates due to a polyurethane acrylate (PUA) binding domain, whereas displaying an integrin-binding domain (RGD) to facilitate consistent and physiologically relevant cell adhesion to the patterned surface. The chimeric peptide treated surfaces were shown to have comparable ability to promote cell adhesion on PUA substrates compared to a standard ECM protein coating (i.e., fibronectin). Additionally, when coupled with this chimeric cell adhesion peptide, a narrow range of nanogroove dimensions were found to enhance the organization and structural maturation of individual human induced pluripotent stem cell-derived cardiomyocytes. These results will be of significant value to researchers seeking to investigate cardiomyocyte development within more highly defined culture conditions for both clinical and basic science applications.

\section{MATERIALS AND METHODS}

\subsection{Fabrication of PUA Nanogrid Array}

Nanopatterned surfaces were comprised of a poly(urethane acrylate) (PUA)-based polymer (Norland Optical Adhesive; NOA 76, 6.7 MPa or $6.7 \times 10^{3} \mathrm{kPa}$ ) bound to glass substrates. All substrate fabrication was accomplished using UV-assisted capillary force lithography (CFL) methods described previously (Figure 1A). ${ }^{42}$ Prefabricated silicon masters (first generation master) were used as the starting step in the fabrication of nanopatterned 
substrates. The first generation master had a $4 \times 4$ island pattern with 16 pattern dimensions (Figure $1 \mathrm{~B}$ ). All 16 patterned area had a uniform depth of $500 \mathrm{~nm}$. second generation substrates consisted of PUA 301 (Minuta Technology) with a modulus of $19.8 \mathrm{MPa}$ patterned onto polyester terephthalate (PET) films. Briefly, PUA was drop-dispensed on to clean, first-generation silicon master surfaces without antistick coating (100\% ethanol or xylene treated and dried under $\mathrm{O}_{2} / \mathrm{N}_{2}$ gas). A transparent PET film was then placed over the dispensed PUA. The silicon master, prepolymer, and PET were cured under a UV light $(\lambda=$ $365 \mathrm{~nm}$ ) for $50 \mathrm{~s}$. After curing, the PET film was carefully removed to leave PUA attached to the PET film with a negative of the silicon master nanopattern. These second-generation PUA/PET nanopattern masters were then cured under a UV light for at least $12 \mathrm{~h}$.

Glass slides were cleaned for $20 \mathrm{~min}$ in $100 \%$ ethanol or xylene and dried under $\mathrm{O}_{2} / \mathrm{N}_{2}$ gas before being ozone treated for $10 \mathrm{~min}$ and coated with glass primer (Minuta Technology Co.) to increase adhesion of the NOA polymer to the surface. NOA polymer was drop dispensed on the pretreated glass slide and the nanopatterned PUA/PET second generation master was placed face down on the polymer/glass surface. The NOA/PUA/PET complex was UV cured for $15 \mathrm{~s}$ followed by peeling off the PUA/PET master from the NOA and glass surface. Flat NOA surfaces were made by drop-dispensing NOA onto clean glass coverslips and spin coated to produce thin NOA films on top of glass substrates. All NOAglass surfaces were then cured under a UV light for at least $12 \mathrm{~h}$ prior to use in experiments.

\subsection{Polyurethane Acrylate Binding Peptide (PUABP) Library Screening and Binding Analysis}

Biotinylated PUABP candidates were incubated on PUA substrates at $37^{\circ} \mathrm{C}$ for at least $12 \mathrm{~h}$, after which substrates were then washed extensively to leave the surface with tightly bound peptides (Figure S1). A streptavidin-Alexa fluorescent conjugate (ThermoFisher) was then added to determine both the surface coverage and degree of immobilization of the PUABP candidates on PUA. Fluorescence intensity was recorded at room temperature with a Safire fluorophotometer (Tecan) at $519 \mathrm{~nm}$ emission and $495 \mathrm{~nm}$ excitation wavelengths. The binding assays were carried out at least in triplicate and across 4 independent assays. The amino acid sequences and the physicochemical properties of the rational peptide library used in the study are shown in Table S1.

Analysis of surface coverage of PUABP1 and PUABP2 was accomplished using a method similar to that described above during the peptide screening of the PUABP library. Biotinylated PUABP1 and PUABP2 candidates were immobilized on PUA surfaces, and the peptide layer was visualized using streptavidin-Alexa fluorescent labeling and fluorescence microscopy (TE 300L, Nikon) using a FITC filter (exciter 460-500, dichroic 505, emitter 510-560; Chroma Technology Co.). The fluorescence intensities on the surfaces were recorded on four random areas via METAMORPH (Universal Imaging) imaging software that were further analyzed and quantified using the ImageJ (National Institutes of Health) image processing and analysis software.

The peptide-PUA binding was further quantified by measuring the fluorescence intensities at several peptide concentrations. To determine the dissociation constant $\left(K_{\mathrm{D}}\right)$ of both PUABP 
peptides, we fitted the experimental fluorescence intensity values to the Langmuir adsorption model using a least-squares regression.

\subsection{Synthesis and Characterization of the Polyurethane Acrylate Binding Peptide-Arg-Gly- Asp (PUABP-RGD)}

Chimeric PUA binding peptide 1 + RGD (PUABP1-RGD; molecular weight: 2155.4) and PUABP2 + RGD (PUABP2-RGD; molecular weight: 2011.3) were both produced through solid-state synthesis using a CSBioe 336s automated peptide synthesizer on Wang resin via Fmoc chemistry and HBTU activation. The crude PUABP-RGD peptides were purified by reverse phase high performance liquid chromatography. The correct sequence and purity of synthetic chimeric PUABP-RGD peptides were verified by mass spectroscopy using a MALDI-TOF mass spectrometer (Table S2 and Figure S2).

\subsection{Differentiation of Human-Induced Pluripotent Stem Cells into Cardiomyocytes}

Cardiomyocyte differentiation was accomplished using a previously established protocol. ${ }^{43}$ Undifferentiated human IMR90-induced pluripotent stem cells, originally derived from fetal lung fibroblasts (James A. Thomson, University of Wisconsin-Madison), were expanded using mouse embryonic fibroblast-conditioned medium supplemented with $5 \mathrm{ng} / \mathrm{mL}$ basic fibroblast growth factor (R\&D systems). Cardiomyocytes were obtained using a directed differentiation method that involved the serial application of activin A (R\&D systems) and bone morphogenetic protein-4 (BMP4, R\&D systems) under serum-free, monolayer culture conditions. At specific points in the early stages of differentiation, the cultures were also supplemented with the Wnt agonist CHIR 99021 (Tocris), followed by the Wnt antagonist Xav 939 (Tocris). After 7 days of in vitro culture, cells were fed every other day with serumfree RPMI (Invitrogen) supplemented with B-27 supplement (Invitrogen) and L-glutamine (Life Technologies). Only cell preparations containing at least $80 \%$ cardiac troponin Tpositive cardiomyocytes (by flow cytometry) were used for the described experiments.

\subsection{Cardiomyocyte Culture}

Differentiated IMR90 cardiomyocytes were dispersed using 0.05\% trypsin-EDTA (Gibco) and replated at a density of 15,000 cells $/ \mathrm{cm}^{2}$ on experimental surfaces for single-cell analysis. Culture medium (RPMI + B27 + Insulin) was changed every other day throughout the experiment. Prior to cell seeding, substrates were coated with PUABP-RGD $(100 \mu \mathrm{M})$ peptides or fibronectin (50 $\mu \mathrm{g} / \mathrm{cm}^{2}$, BD Biosciences) and incubated overnight at $37^{\circ} \mathrm{C}$. All structural analyses were performed following 21 days on experimental substrates ( $\sim 40$ days total culture period).

\subsection{Immunostaining}

Cells were fixed at the end of the 3-week culture period with $4 \%$ paraformaldehyde (Affymetrix). Cells were then rinsed twice with PBS and permeabilized with $0.1 \%$ TritonX-100 (Sigma) in PBS for 10 min. Permeabilized samples were blocked with $1 \%$ bovine serum albumin (BSA, Sigma) in PBS for 40-60 min at room temperature. A mouse primary antibody against $a$-actinin (Sigma) was then diluted 1:1000 in PBS supplemented with 5\% BSA, and incubated for $1 \mathrm{~h}$ at room temperature. A secondary antibody (goat antimouse 
Alexa Fluor-594, Life Technologies) was diluted in PBS supplemented with 5\% BSA to match the dilution of primary antibody. In addition, conjugated Alexa Fluor 488-phalloidin (Life Technologies) was added to the secondary antibody solution to facilitate F-actin staining. Samples were incubated at $37^{\circ} \mathrm{C}$ with the secondary antibody solution for $1 \mathrm{~h}$. Finally, samples were washed with PBS, and mounted onto glass microscope slides with VectaShield (Vector). A DAPI counterstain was included with the mounting medium for visualizing nuclei. Stained cells were stored at $4{ }^{\circ} \mathrm{C}$ until analysis via confocal microscopy.

\subsection{Morphological Analysis}

At least 5 images were taken for each experimental condition to obtain sample sizes in the range of 60 to 90 cells per condition. Image $(\mathrm{NIH})$ software was then used to determine cell area, cell perimeter, sarcomere length, and major and minor axis lengths (to provide a measure of circularity). Custom written MATLAB code, which analyzed the orientation of phalloidin-stained F-actin fibers within the cell, was used to assess the alignment of actin fibers within cultured cells with respect to the direction of the pattern as detailed previously. ${ }^{43,44}$ Measurements for each condition were compiled, and the percentage of cells within $5^{\circ}$ of the underlying pattern direction was computed.

\subsection{Statistical Analysis}

All statistical analysis was performed using Microsoft Excel and Prism (GraphPad Software). One-way analysis of variance (ANOVA) tests were performed to determine the statistical significance of observed differences in cell structure from cultures maintained on different dimension nanotopographies, with suitable post hoc analyses performed to determine which specific conditions were statistically different from each other. A one-way ANOVA was also used to compare the binding affinity of streptavidin-Alexa fluorescent conjugates to surfaces treated with PUABP1, PUABP2, and untreated controls. A two-way ANOVA with suitable post hoc test for multiple comparisons was used to compare the binding affinity of hiPSC-CMs to surfaces treated with PUABP1, PUABP2, and fibronectin controls across multiple nanopattern dimensions. In all experiments, a p value less than 0.05 was considered statistically significant.

\section{RESULTS}

\subsection{Fabrication of Nanogrid Cell Culture Substrates for High-Throughput Study of Nanotopography-Induced Sarcomeric Development in Cardiomyocytes}

The PUA nanogrid cell culture array used in this study was fabricated using CFL (Figure $1 \mathrm{~A})$, and was comprised of a $5 \times 5 \mathrm{~mm}$ nanopattern square with varying topographic dimensions arranged in a $4 \times 4$ grid. All patterns consisted of a parallel array of nanoscale grooves and ridges with a 1:1 groove width:ridge width ratio (same geometry) and groove/ ridge widths of 350, 400, 450, 500, 600, 700, 750, 800, 900, 1000, 1200, 1250, 1500, 1600, 1800 , or $2000 \mathrm{~nm}$ (Figure 1B). PUA substrates without any topographic patterning were used as "flat" controls. These nanogrid arrays were fabricated on single glass coverslips, 25 $\mathrm{mm}$ in diameter, thereby allowing for the high-throughput analysis of cardiomyocyte structural development due to topographical cues while reducing experimental variability with regards to cell and medium batches. 


\subsection{Characterization of Chimeric Peptide Library Binding Affinities onto Nanopatterned Substrates}

PUA-binding peptide domains were screened from a rationally selected set of 15 peptide candidates that were previously reported to bind to polymeric materials. ${ }^{37-40}$ In the screening assay, biotinylated PUABP candidates were allowed to self-assemble on nonpatterned PUA substrates where they interacted with streptavidin-Alexa conjugates to produce a fluorescent signal, and the intensity of this signal was quantified to determine the amount of peptide bound to the substrate (Figure 2A). From surface binding assays, five of the tested peptides produced a quantifiable fluorescence signal $(n=4$, Figure $2 \mathrm{~B})$. The two peptides with the greatest binding signals were selected for further PUA binding characterization, and were designated PUABP1 and PUABP2.

The selected peptides displayed a uniform surface coverage across the PUA substrate as verified by fluorescence imaging, while controls (bare surface and SA-Alexa without PUABP-biotin treated samples) displayed no discernible fluorescence (Figure 2C). Both peptides produced significantly greater fluorescence levels than control substrates $(p<0.05)$, and the average fluorescence readings for PUABP2 treated samples were significantly higher than those recorded from PUABP1 treated samples $(p<0.05)$ (Figure 2D).

The dissociation constant values $\left(\mathrm{K}_{\mathrm{D}}\right)$ for the selected peptides were calculated using Langmuir adsorption isotherms using the surface coverage values generated from fluorescence intensities at different peptide concentrations (0.001-100 $\mu \mathrm{M}$ range). Peptides exhibited subnanomolar to micromolar binding affinities to PUA, with $\mathrm{K}_{\mathrm{D}}$ values of 2.97 $\mu \mathrm{M}$ and $0.34 \mu \mathrm{M}$ for PUABP1 and PUABP2, respectively (Figure 2E). Peptide saturation on PUA was obtained at $100 \mu \mathrm{M}$, and this peptide concentration was used in all subsequent biological experiments.

To engineer the biomimetic interface for cell adhesion assessment, we next designed the chimeric peptides to integrate PUA surface recognition and self-assembling functionalities with a cell-binding capacity. The selected PUABP peptides, PUABP1 and PUABP2, were linked to the integrin binding peptide RGD with a flexible SGGG peptide spacer region to ensure both functionalities remained preserved. ${ }^{45,46}$ The resulting chimeric conjugates were abbreviated as PUABP1-RGD and PUABP2-RGD (Table 2 and Figure S1).

\subsection{Assessment of Cell Attachment on Chimeric Peptide Functionalized Nanopatterned Substrates}

Human cardiomyocytes were differentiated from an established induced pluripotent stem cell line (IMR90) using previously published methods (Figure 3a). ${ }^{43,47}$ Differentiated cells were plated on nanogrid arrays coated with either PUABP1-RGD or PUABP2-RGD peptides. Fibronectin $(50 \mu \mathrm{g} / \mathrm{mL})$ treated surfaces were also examined as a control. After 24 $\mathrm{h}$ in culture, attached cells were counted for each pattern design and each surface treatment tested (Figure 3b). There were no significant differences observed in cell attachment between pattern dimensions or fibronectin coating $(p>0.05)$. Although it was expected that the change in substrate topographic dimensions would elicit different cell responses over time, the initial attachment similarities suggests uniform cell dispersion across all 
experimental conditions. This ensured that observed differences in cellular development and maturation at later time-points were not simply due to differences in initial cell attachment, but rather to fundamental differences in cellular responses to the underlying topographic signals. Given the uniformity in cell attachment for all surface treatments, and the higher biotin binding affinity results for PUABP2 over PUABP1, PUABP2-RGD surface treatments were employed for all subsequent analyses.

\subsection{Effects of Nanotopographic Pattern Dimensions on Cardiomyocyte Morphology}

We evaluated the structural development of hiPSC-derived cardiomyocytes cultured on PUABP2-RGD treated nanopatterned substrates for 3 weeks by analyzing their cell area, perimeter, circularity, and anisotropy. Analysis highlighted significant differences in cell area, an important structural indicator of hiPSC-CM maturation, between cultures maintained on different surface patterns $(p<0.0001)$. Cell area on $800 \mathrm{~nm}$ wide nanopatterns was significantly larger than the cell area recorded on all other surfaces except $750 \mathrm{~nm}$ patterns. All pattern dimensions between 600 and $1200 \mathrm{~nm}$ promoted the development of significantly larger cell areas than was achieved on flat controls. Pattern dimensions below $600 \mathrm{~nm}$ or above $1200 \mathrm{~nm}$, however, produced cells with areas not significantly different from flat surfaces (Figure 4a).

Cell perimeter is another structural cardiac development marker, providing an indication of nonpathological cellular hypertrophy. ${ }^{47,48}$ As was seen with the analysis of cell area, the capacity for intermediate nanopattern dimensions to promote increases in cultured cell perimeter was observed. Cell perimeters exhibited significant differences between different surface patterns and flat controls $(p<0.0001)$. Specifically, cell perimeters on nanopatterns between 600 and $900 \mathrm{~nm}$ were significantly greater than all other experimental conditions, but were not significantly different from each other $(p>0.05)$ (Figure $4 b)$.

Given the considerable importance of structural anisotropy in cardiomyocytes in vivo, ${ }^{44}$ circularity becomes a valuable analytical tool when determining structural development of hiPSC-CMs in vitro. The single adult cardiomyocyte typically exhibits a rectangular elongated cell body with myofibrils aligned in parallel and a length:width ratio of 7:1.49 Immature cardiomyocytes, on the other hand, possess a much more rounded morphology with disorganized myofibril structures. Therefore, a measurement of cell elongation via circularity indices, where an index of 1 indicates a perfect circle and an index of 0 indicates a straight line, provides a further indication of hiPSC-CM structural maturity. Evaluation of the circularity index of single hiPSC-CMs on different nanotopographies showed that the circularity index was significantly reduced on all patterns compared to flat controls and 2000 $\mathrm{nm}$ topographies $(p<0.0001)$. There were no significant differences between any other experimental groups (though those between 700 and 1000 tended to be lowest), indicating that all nanopattern designs, with the exception of $2000 \mathrm{~nm}$ ones, were equally capable of promoting the development of cellular anisotropy in this in vitro system (Figure 4c).

Cell orientation was also evaluated as a measure of the degree to which cells responded to the underlying patterns. It was expected that the ability of cultured hiPSC-CMs to penetrate into nanogrooves would strongly influence overall cell alignment. As expected, the highest percentage of cells falling within 5 degrees of the pattern direction was achieved on $800 \mathrm{~nm}$ 
patterns $(86.57 \%$ of all cells examined; $\mathrm{n}=67)$. By comparison, just $25.93 \%$ of cells counted on $350 \mathrm{~nm}$ patterns $(n=81)$ fell within 5 degrees of the pattern direction. On 2000 $\mathrm{nm}$ patterns, $41.79 \%$ of counted cells $(n=67)$ fell within 5 degrees of the pattern direction, providing an indication of the degree of alignment variance between the largest and smallest pattern dimensions. All patterned surfaces promoted greater alignment than flat controls, on which only $6.32 \%$ of counted cells $(n=95)$ fell within 5 degrees of the pattern direction on other surfaces (Figure $4 \mathrm{~d}$ ).

\subsection{Effects on Nanotopographic Pattern Dimensions on Sarcomere Development}

Finally, immunostained images of hiPSC-CMs were used to evaluate the sarcomere length within cells cultured on each pattern dimension (Figure 5a). Sarcomere length is directly related to force production from cell contractions, ${ }^{50,51}$ and can be correlated to the FrankStarling law on the nanoscale. ${ }^{52}$ It has been reported that adult cardiomyocytes have sarcomere lengths in the region of $1.8-2.0 \mu \mathrm{m}$, whereas immature human pluripotent stem cell-derived cardiomyocytes often have sarcomere lengths of approximately $1.5 \mu \mathrm{m} .{ }^{47,53-56}$

Under the described experimental conditions, we report a maximum sarcomere length in cells maintained on intermediate pattern dimensions (Figure 5b). There was a significant increase in the sarcomere length of cells maintained on topographies with feature dimensions between 750 and $1000 \mathrm{~nm}$ and cells grown on all other patterns $(p<0.0001)$. No significant differences in sarcomere length were observed between cells maintained on 750 , 800,900 , and $1000 \mathrm{~nm}$ patterns ( $p>0.05$ ). The sarcomere length of cells on $800 \mathrm{~nm}$ substrates was $1.85 \mu \mathrm{m}( \pm 0.056)$, which is a substantial increase in length compared to other studies on hiPSC-CMs of a similar age $(1.65 \pm 0.02) .{ }^{47}$ We posit that the presence of an underlying topographic pattern with optimal dimensions promoted the structural organization of the internal cytoskeleton, which led to improved myofibril organization and sarcomere length development, a hallmark of cardiomyocyte maturation.

\section{DISCUSSION}

Despite the tremendous potential offered by advances in stem cell technologies, a lack of understanding with regards to how to drive the biomimetic development of hiPSC-derived cardiomyocytes in vitro has so far limited their effectiveness in drug screening, disease modeling, and mechanistic studies. This has led to numerous efforts to develop an in vitro environment that more closely mimics the native environmental features of the myocardium to facilitate correct phenotypic development. However, the current ability to achieve mature cells remains limited due to the complexity involved in native microenvironment recapitulation. We developed a nanogrid array comprised of parallel grooves with dimensions ranging from 350 to $2000 \mathrm{~nm}$ arranged as a $4 \times 4$-grid configuration using CFL. ${ }^{42}$ To create a more biologically relevant culture platform, we designed this array to mimic the complex ECM structure of the myocardial basement membrane. The cardiac ECM is made up of collagen fiber networks that range in size from a few hundred nanometers to several micrometers, ${ }^{15,57}$ and analysis of the in vivo cardiac environment has indicated that the underlying ECM topography strongly influences the alignment and subsequent function of cardiac tissues. The CFL technique employed herein allows for the 
simple and reproducible generation of nanoscale features with high fidelity across large platforms like the one used in this study, thus making it possible to screen 16 distinct nanopattern designs in a single well in order to evaluate optimal substrate conditions for promoting cellular structural development in vitro.

To produce a biomimetic interface which may provide biologically and physiologically relevant surface properties, we designed a chimeric peptide comprising of a cell adhesion domain to facilitate cell adhesion, and a surface recognition domain to provide PUA binding with a controllable surface distribution. In the chimeric peptide design, the highly conserved RGD integrin-binding sequence was used as the cell adhesion domain, while for the surface recognition domain, peptides that can selectively bind to PUA substrates were screened from a rationally designed subset of biocombinatorially selected peptides (PUABP) (Table S1).

The collected cell adhesion data demonstrate that cell attachment to the chimeric peptide and control fibronectin treated substrates was comparable on all topographic surfaces examined. The fact that cell attachment on PUABP-RGD-coated substrates was comparable to fibronectin treated controls highlights the applicability of the biomimetic interface design as a suitable surface treatment method for cardiomyocyte culture. The establishment of a peptide-mediated surface coating that incorporates selective surface binding with the desired bioactivity may provide a benefit in promoting the formation of more robust cardiomyocyte monolayers in future studies. Furthermore, the potential to bind the PUABP motif to other antigens for recognition and binding of specific cells is a credible application for this technology in the near future. Comparable cell binding observed on PUABP-RGD and fibronectin treated substrates highlights that synthetically manufactured peptides are capable of functioning equally well as biopolymers in a cell culture setting. Given the high cost associated with isolation and purification of human fibronectin, PUABP-RGD represents a credible cost-effective alternative for large-scale industrial cell culture.

Morphological analysis of hiPSC-CMs cultured on PUABP2-RGD functionalized substrates for 21 days showed increased cell alignment, area, and sarcomere lengths in cells maintained on intermediate topographies, with a peak in structural maturation observed on $800 \mathrm{~nm}$ features. These data are in accordance with previous work performed using rodent cells, demonstrating that human cardiomyocytes are similarly capable of responding to exogenous structural cues to generate more biomimetic in vitro cardiac cultures. ${ }^{58}$ Furthermore, the results indicate that an ideal range for topography-induced cardiomyocyte development exists in the upper nanometer range. Ultrastructural analysis of the native myocardial ECM reveals aligned fibrils approximately $100 \mathrm{~nm}$ in diameter, with previous reports of collagen fibrils varying in diameter from 30 to $120 \mathrm{~nm} .{ }^{59}$ Although both are in the nanometer range, comparison of in vitro and in vivo data suggests that larger topographies are required in vitro to promote cardiomyocyte maturation than cells would likely be exposed to in vivo. This disparity is likely attributable to the inherent differences in 3D and 2D cellular environments. In 3D, cardiac cells are surrounded and pressed on all sides by ECM fibers and other cells oriented uniaxially. As such, they would likely be more receptive to the mechanical cues that surround them on all sides. In 2D, cultured cells are less mature, and only influenced by topographical cues on a single plane. Consequently, it seems plausible that such cells would require significantly more pronounced structural cues to guide their uniaxial development and maturation. Additionally, it has been reported that the width of the 
grooves on a topographically patterned substrate directly affects the ability of cultured cell bodies to penetrate the topography. ${ }^{15,60}$ The penetration level of a given cell influences the degree to which that cell will elongate and align with the underlying pattern, which in turn affects the degree to which the pattern is able to drive cellular development and maturation in vitro. ${ }^{16}$ As cells are less able to penetrate into smaller groove widths, the influence of the topography becomes less apparent on extremely narrow topographies. However, cells seeded onto much larger groove widths also encounter problems that inhibit their ability to induce structural maturation. As the widths become extremely large (micron scale), cells become isolated on top of ridges or within individual grooves, and the section of the cell that interacts with the underlying substrate is not able to respond to the substrate directional cues, as it only comes into contact with the surface of a ridge (which appears flat) or the bottom of a single groove. Therefore, our results suggest the existence of optimal groove-ridge dimensions that are wide enough to influence cellular orientation and maturation, but narrow enough to enable the cell to detect the underlying physical cues, thereby highlighting the differing ability of cultured cells to respond to varied nanotopographic cues.

A critical point for the future application of hiPSC-CMs is the drastically reduced cell circularity on nanopatterned cultures compared to flat controls observed at a 3-week time point. Lundy et al. reported a similar reduction in hiPSC-CM circularity on flat culture substrates following substantially protracted culture periods. ${ }^{47}$ Late stage ( 100 day) circularity measurements from this study were similar to those found in our analysis of cells on nanopatterned substrates after only 3 weeks ( 21 days postreplating, $\sim 40$ days total culture time). From this comparison, it is clear that the presence of underlying ECM topography promotes improved structural maturity in cultured hiPSC-CMs at a far faster rate than is achievable on conventional flat culture surfaces. Such a result highlights the importance of nanotopographic surfaces for stem-cell-based cardiac bioengineering where mature phenotypes are desired with shorter lead times.

\section{CONCLUSION}

We have detailed the development of a platform in which different nanogroove widths can be used to examine structural maturation in human iPSC-derived cardiomyocytes in a highthroughput manner. Using this system, we highlight that human cardiac cells respond to exogenous structural cues by orienting into a parallel array that more closely mimics the structure of the native mammalian myocardium. The developed platform incorporates a chimeric peptide, PUABP2-RGD, as an alternative to conventional biopolymers such as fibronectin for achieving a defined, cost-effective, and reproducible surface coating for promoting cardiomyocyte attachment. Future studies could focus on other similarly bioactive molecules (that activate signaling pathways such as Wnt) for application in the development of biomimetic interfaces for promoting cellular development and maturation in vitro. ${ }^{46}$ The collected results highlight the improved cellular development on surfaces that mimic the physical alignment of the native ECM. Previous studies have found that substrate elasticity that recapitulates what is observed in vivo are better suited to promoting cardiomyocyte structural and functional maturation. ${ }^{16,61,62}$ Given that, these results further highlight how accurate recreation of the myocardial niche is advantageous in promoting cellular development in vitro. This study will be of significant value to researchers seeking 
to develop in vitro platforms capable of promoting hiPSC-CM maturation for drug screening, disease modeling, and cardiac developmental studies in the near future.

\section{Supplementary Material}

Refer to Web version on PubMed Central for supplementary material.

\section{Acknowledgments}

This work was supported by an American Heart Association (AHA) Scientist Development Grant (13SDG14560076), a Washington State Life Sciences Discovery Fund grant, an International Collaborative R\&D Program Grant with KIAT funded by the MOTIE (N0000894) awarded to D.H.K., and partially by a NIH-NIAMS grant (AR062249-03) awarded to C.T. Additionally, X.Y. was supported by AHA Postdoctoral Fellowships (12POST11940060 and 14POST20310023). A.S.T.S. was supported by an NIH T32 postdoctoral fellowship (2T32HL007312-36A1). C.E.M. was supported by the following grants from the NIH: R01 HL084642, P01 HL094374, P01 GM81619, and U01 HL100405. M.R. was supported by the following grants from the NIH: R01 HL111197, R01 HD048895.

\section{References}

1. Liu WH, Chang YL, Lo WL, Li HY, Hsiao CW, Peng CH, Chiou SH, Ma HI, Chen SJ. Human Induced Pluripotent Stem Cell and Nanotechnology-Based Therapeutics. Cell Transplant. 2015; 24:2185-2195. [PubMed: 25299513]

2. Wikswo JP. The Relevance and Potential Roles of Microphysiological Systems in Biology and Medicine. Exp Biol Med. 2014; 239:1061-1072.

3. Lancaster MA, Knoblich JA. Organogenesis in a Dish: Modeling Development and Disease Using Organoid Technologies. Science. 2014; 345:1247125. [PubMed: 25035496]

4. Acimovic I, Vilotic A, Pesl M, Lacampagne A, Dvorak P, Rotrekl V, Meli AC. Human Pluripotent Stem Cell-Derived Cardiomyocytes as Research and Therapeutic Tools. BioMed Res Int. 2014; 2014:1.

5. Gherghiceanu M, Barad L, Novak A, Reiter I, Itskovitz-Eldor J, Binah O, Popescu LM. Cardiomyocytes Derived from Human Embryonic and Induced Pluripotent Stem Cells: Comparative Ultrastructure. J Cell Mol Med. 2011; 15:2539-2551. [PubMed: 21883888]

6. Jonsson MK, Vos MA, Mirams GR, Duker G, Sartipy P, de Boer TP, van Veen TA. Application of Human Stem Cell-Derived Cardiomyocytes in Safety Pharmacology Requires Caution Beyond HERG. J Mol Cell Cardiol. 2012; 52:998-1008. [PubMed: 22353256]

7. Dunn DA, Hodge AJ, Lipke EA. Biomimetic Materials Design for Cardiac Tissue Regeneration. Wiley Interdiscip Rev: Nanomed Nanobiotechnol. 2014; 6:15-39. [PubMed: 24123919]

8. Kim DH, Kim P, Song I, Cha JM, Lee SH, Kim B, Suh KY. Guided Three-Dimensional Growth of Functional Cardiomyocytes on Polyethylene Glycol Nanostructures. Langmuir. 2006; 22:54195426. [PubMed: 16732672]

9. Zhang D, Shadrin IY, Lam J, Xian HQ, Snodgrass HR, Bursac N. Tissue-Engineered Cardiac Patch for Advanced Functional Maturation of Human ESC-Derived Cardiomyocytes. Biomaterials. 2013; 34:5813-5820. [PubMed: 23642535]

10. Yang X, Rodriguez M, Pabon L, Fischer KA, Reinecke H, Regnier M, Sniadecki NJ, RuoholaBaker H, Murry CE. Triiodo-l-thyronine Promotes the Maturation of Human CardiomyocytesDerived from Induced Pluripotent Stem Cells. J Mol Cell Cardiol. 2014; 72:296-304. [PubMed: 24735830]

11. Thavandiran N, Nunes SS, Xiao Y, Radisic M. Topological and Electrical Control of Cardiac Differentiation and Assembly. Stem Cell Res Ther. 2013; 4:14. [PubMed: 23425700]

12. Streeter DD Jr, Hanna WT. Engineering Mechanics for Successive States in Canine Left Ventricular Myocardium II. Fiber Angle and Sarcomere Length. Circ Res. 1973; 33:656-664. [PubMed: 4762007] 
13. Sosnovik DE, Wang R, Dai G, Wang T, Aikawa E, Novikov M, Rosenzweig A, Gilbert RJ, Wedeen VJ. Diffusion Spectrum MRI Tractography Reveals the Presence of a Complex Network of Residual Myofibers in Infarcted Myocardium. Circ Cardiovasc Imaging. 2009; 2:206-212. [PubMed: 19808594]

14. Jiao A, Trosper NE, Yang HS, Kim J, Tsui JH, Frankel SD, Murry CE, Kim DH. Thermoresponsive Nanofabricated Substratum for the Engineering of Three-Dimensional Tissues with Layer-by-Layer Architectural Control. ACS Nano. 2014; 8:4430-4439. [PubMed: 24628277]

15. Kim DH, Lipke EA, Kim P, Cheong R, Thompson S, Delannoy M, Suh KY, Tung L, Levchenko A. Nanoscale Cues Regulate the Structure and Function of Macroscopic Cardiac Tissue Constructs. Proc Natl Acad Sci U S A. 2010; 107:565-570. [PubMed: 20018748]

16. Wang PY, Yu J, Lin JH, Tsai WB. Modulation of Alignment, Elongation and Contraction of Cardiomyocytes Through a Combination of Nanotopography and Rigidity of Substrates. Acta Biomater. 2011; 7:3285-3293. [PubMed: 21664306]

17. Diehl KA, Foley JD, Nealey PF, Murphy CJ. Nanoscale Topography Modulates Corneal Epithelial Cell Migration. J Biomed Mater Res, Part A. 2005; 75:603-611.

18. Biela SA, Su Y, Spatz JP, Kemkemer R. Different Sensitivity of Human Endothelial Cells, Smooth Muscle Cells and Fibroblasts to Topography in the Nano-Micro Range. Acta Biomater. 2009; 5:2460-2466. [PubMed: 19410529]

19. Wang J, Chen A, Lieu DK, Karakikes I, Chen G, Keung W, Chan CW, Hajjar RJ, Costa KD, Khine M, Li RA. Effect of Engineered Anisotropy on the Susceptibility of Human Pluripotent Stem CellDerived Ventricular Cardiomyocytes to Arrhythmias. Biomaterials. 2013; 34:8878-8886. [PubMed: 23942210]

20. Kim DH, Provenzano PP, Smith CL, Levchenko A. Matrix Nanotopography as a Regulator of Cell Function. J Cell Biol. 2012; 197:351-360. [PubMed: 22547406]

21. Miyagi Y, Chiu LL, Cimini M, Weisel RD, Radisic M, Li RK. Biodegradable Collagen Patch with Covalently Immobilized VEGF for Myocardial Repair. Biomaterials. 2011; 32:1280-1290. [PubMed: 21035179]

22. Porter AM, Klinge CM, Gobin AS. Biomimetic Hydrogels with VEGF Induce Angiogenic Processes in Both HUVEC and HMEC. Biomacromolecules. 2011; 12:242-246. [PubMed: 21128597]

23. Koo LY, Irvine DJ, Mayes AM, Lauffenburger DA, Griffith LG. Co-Regulation of Cell Adhesion by Nanoscale RGD Organization and Mechanical Stimulus. J Cell Sci. 2002; 115:1423-1433. [PubMed: 11896190]

24. Israeli-Rosenberg S, Manso AM, Okada H, Ross RS. Integrins and Integrin-Associated Proteins in the Cardiac Myocyte. Circ Res. 2014; 114:572-586. [PubMed: 24481847]

25. Hersel U, Dahmen C, Kessler H. RGD Modified Polymers: Biomaterials for Stimulated Cell Adhesion and Beyond. Biomaterials. 2003; 24:4385-4415. [PubMed: 12922151]

26. Ruoslahti E. RGD and Other Recognition Sequences for Integrins. Annu Rev Cell Dev Biol. 1996; 12:697-715. [PubMed: 8970741]

27. Clyman RI, McDonald KA, Kramer RH. Integrin Receptors on Aortic Smooth Muscle Cells Mediate Adhesion to Fibronectin, Laminin, and Collagen. Circ Res. 1990; 67:175-186. [PubMed: 1694736]

28. Pence JC, Gonnerman EA, Bailey RC, Harley BA. Strategies to Balance Covalent and NonCovalent Biomolecule Attachment Within Collagen-GAG Biomaterials. Biomater Sci. 2014; 2:1296-1304. [PubMed: 25147727]

29. Solouk A, Cousins BG, Mirahmadi F, Mirzadeh H, Nadoushan MR, Shokrgozar MA, Seifalian AM. Biomimetic Modified Clinical-Grade POSS-PCU Nanocomposite Polymer for Bypass Graft Applications: A Preliminary Assessment of Endothelial Cell Adhesion and Haemocompatibility. Mater Sci Eng, C. 2015; 46:400-408.

30. Krishnamoorthy G, Sehgal PK, Mandal AB, Sadulla S. Novel Collagen Scaffolds Prepared by Using Unnatural D-Amino Acids Assisted EDC/NHS Crosslinking. J Biomater Sci, Polym Ed. 2013; 24:344-364. [PubMed: 23565652] 
31. Ye L, Wu X, Mu Q, Chen B, Duan Y, Geng X, Gu Y, Zhang A, Zhang J, Feng ZG. HeparinConjugated PCL Scaffolds Fabricated by Electrospinning and Loaded with Fibroblast Growth Factor 2. J Biomater Sci, Polym Ed. 2011; 22:389-406. [PubMed: 20566037]

32. Yazici H, Fong H, Wilson B, Oren EE, Amos FA, Zhang H, Evans JS, Sarikaya M, Tamerler C. Biological Response on a Titanium Implant-Grade Surface Functionalized with Modular Peptides. Acta Biomater. 2013; 9:5341-5352. [PubMed: 23159566]

33. Sarikaya M, Tamerler C, Jen AKY, Schulten K, Baneyx F. Molecular Biomimetics: Nanotechnology Through Biology. Nat Mater. 2003; 2:577-585. [PubMed: 12951599]

34. Tamerler C, Sarikaya M. Molecular Biomimetics: Utilizing Nature's Molecular Ways in Practical Engineering. Acta Biomater. 2007; 3:289-299. [PubMed: 17257913]

35. Tamerler C, Sarikaya M. Molecular Biomimetics: Genetic Synthesis, Assembly, and Formation of Materials Using Peptides. MRS Bull. 2008; 33:504-510.

36. Tamerler C, Sarikaya M. Molecular Biomimetics: Nanotechnology and Bionanotechnology Using Genetically Engineered Peptides. Philos Trans R Soc, A. 2009; 367:1705-1726.

37. Date T, Sekine J, Matsuno H, Serizawa T. Polymer-Binding Peptides for the Noncovalent Modification of Polymer Surfaces: Effects of Peptide Density on the Subsequent Immobilization of Functional Proteins. ACS Appl Mater Interfaces. 2011; 3:351-359. [PubMed: 21288050]

38. Sawada, T., Serizawa, T. Peptide Materials: From Nanostructures to Applications. Alemán, C.Bianco, A., Venanzi, M., editors. John Wiley \& Sons; Chichester, U.K: 2013. p. 417-433.Chapter 15

39. Serizawa T, Sawada T, Matsuno H. Highly Specific Affinities of Short Peptides Against Synthetic Polymers. Langmuir. 2007; 23:11127-11133. [PubMed: 17910487]

40. Sanghvi AB, Miller KPH, Belcher AM, Schmidt CE. Biomaterials Functionalization Using a Novel Peptide that Selectively Binds to a Conducting Polymer. Nat Mater. 2005; 4:496-502. [PubMed: 15895095]

41. Hnilova M, Oren EE, Seker UOS, Wilson BR, Collino S, Evans JS, Tamerler C, Sarikaya M. Effect of Molecular Conformations on the Adsorption Behavior of Gold-Binding Peptides. Langmuir. 2008; 24:12440-12445. [PubMed: 18839975]

42. Macadangdang J, Lee HJ, Carson D, Jiao A, Fugate J, Pabon L, Regnier M, Murry C, Kim DH. Capillary Force Lithography for Cardiac Tissue Engineering. J Visualized Exp. 2014; 88doi: $10.3791 / 50039$

43. Zhu WZ, Van Biber B, Laflamme MA. Methods for the Derivation and Use of Cardiomyocytes from Human Pluripotent Stem Cells. Methods Mol Biol. 2011; 767:419-431. [PubMed: 21822893]

44. Badie N, Satterwhite L, Bursac N. A Method to Replicate the Microstructure of Heart Tissue In Vitro Using DTMRI-Based Cell Micropatterning. Ann Biomed Eng. 2009; 37:2510-2521. [PubMed: 19806455]

45. Yucesoy D, Hnilova M, Boone K, Arnold PM, Snead ML, Tamerler C. Chimeric Peptides as Implant Functionalization Agents for Titanium Alloy Implants with Antimicrobial Properties. JOM. 2015; 67:754-766. [PubMed: 26041967]

46. Zhou Y, Snead ML, Tamerler C. Bio-Inspired Hard-to-Soft Interface for Implant Integration to Bone. Nanomedicine. 2015; 11:431-434. [PubMed: 25461292]

47. Lundy SD, Zhu WZ, Regnier M, Laflamme MA. Structural and Functional Maturation of Cardiomyocytes Derived from Human Pluripotent Stem Cells. Stem Cells Dev. 2013; 22:19912002. [PubMed: 23461462]

48. Kawaguchi-Manabe H, Ieda M, Kimura K, Manabe T, Miyatake S, Kanazawa H, Kawakami T, Ogawa S, Suematsu M, Fukuda K. A Novel Cardiac Hypertrophic Factor, Neurotrophin-3, is Paradoxically Downregulated in Cardiac Hypertrophy. Life Sci. 2007; 81:385-392. [PubMed: 17628607]

49. Bray MA, Sheehy SP, Parker KK. Sarcomere Alignment is Regulated by Myocyte Shape. Cell Motil Cytoskeleton. 2008; 65:641-651. [PubMed: 18561184]

50. Hibberd MG, Jewell BR. Calcium- and Length-Dependent Force Production in Rat Ventricular Muscle. J Physiol. 1982; 329:527-540. [PubMed: 7143258] 
51. Kentish JC, ter Keurs HE, Ricciardi L, Bucx JJ, Noble MI. Comparison Between the Sarcomere Length-Force Relations of Intact and Skinned Trabeculae from Rat Right Ventricle. Influence of Calcium Concentrations on These Relations. Circ Res. 1986; 58:755-768. [PubMed: 3719928]

52. Konhilas JP, Irving TC, de Tombe PP. Frank-Starling Law of the Heart and the Cellular Mechanisms of Length-Dependent Activation. Pfluegers Arch. 2002; 445:305-310. [PubMed: 12466931]

53. Feest ER, Korte FS, Tu AY, Dai J, Razumova MV, Murry CE, Regnier M. Thin Filament Incorporation of an Engineered Cardiac Troponin C Variant (L48Q) Enhances Contractility in Intact Cardiomyocytes from Healthy and Infarcted Hearts. J Mol Cell Cardiol. 2014; 72:219-227. [PubMed: 24690333]

54. Korte FS, Dai J, Buckley K, Feest ER, Adamek N, Geeves MA, Murry CE, Regnier M. Upregulation of Cardiomyocyte Ribonucleotide Reductase Increases Intracellular 2 Deoxy-ATP, Contractility, and Relaxation. J Mol Cell Cardiol. 2011; 51:894-901. [PubMed: 21925507]

55. Yang X, Pabon L, Murry CE. Engineering Adolescence: Maturation of Human Pluripotent Stem Cell-Derived Cardiomyocytes. Circ Res. 2014; 114:511-523. [PubMed: 24481842]

56. Bird SD, Doevendans PA, van Rooijen MA, Brutel de la Riviere A, Hassink RJ, Passier R, Mummery CL. The Human Adult Cardiomyocyte Phenotype. Cardiovasc Res. 2003; 58:423-434. [PubMed: 12757876]

57. Geiger B, Bershadsky A, Pankov R, Yamada KM. Transmembrane Crosstalk Between the Extracellular Matrix and the Cytoskeleton. Nat Rev Mol Cell Biol. 2001; 2:793-805. [PubMed: 11715046]

58. Radisic M, Park H, Shing H, Consi T, Schoen FJ, Langer F, Freed LE, Vunjak-Novakovic G. Functional Assembly of Engineered Myocardium by Electrical Stimulation of Cardiac Myocytes Cultured on Scaffolds. Proc Natl Acad Sci U S A. 2004; 101:18129-18134. [PubMed: 15604141]

59. Robinson TF, Factor SM, Capasso JM, Wittenberg BA, Blumenfeld OO, Seifter S. Morphology, Composition, and Function of Struts Between Cardiac Myocytes of Rat and Hamster. Cell Tissue Res. 1987; 249:247-255. [PubMed: 3621299]

60. Kim DH, Han K, Gupta K, Kwon KW, Suh KY, Levchenko A. Mechanosensitivity of Fibroblast Cell Shape and Movement to Anisotropic Substratum Topography Gradients. Biomaterials. 2009; 30:5433-5444. [PubMed: 19595452]

61. Jacot JG, McCulloch AD, Omens JH. Substrate Stiffness Affects the Functional Maturation of Neonatal Rat Ventricular Myocytes. Biophys J. 2008; 95:3479-3487. [PubMed: 18586852]

62. Engler AJ, Carag-Krieger C, Johnson CP, Raab M, Tang HY, Speicher DW, Sanger JW, Sanger JM, Discher DE. Embryonic Cardiomyocytes Beat Best on a Matrix with Heart-Like Elasticity: ScarLike Rigidity Inhibits Beating. J Cell Sci. 2008; 121:3794-3802. [PubMed: 18957515] 

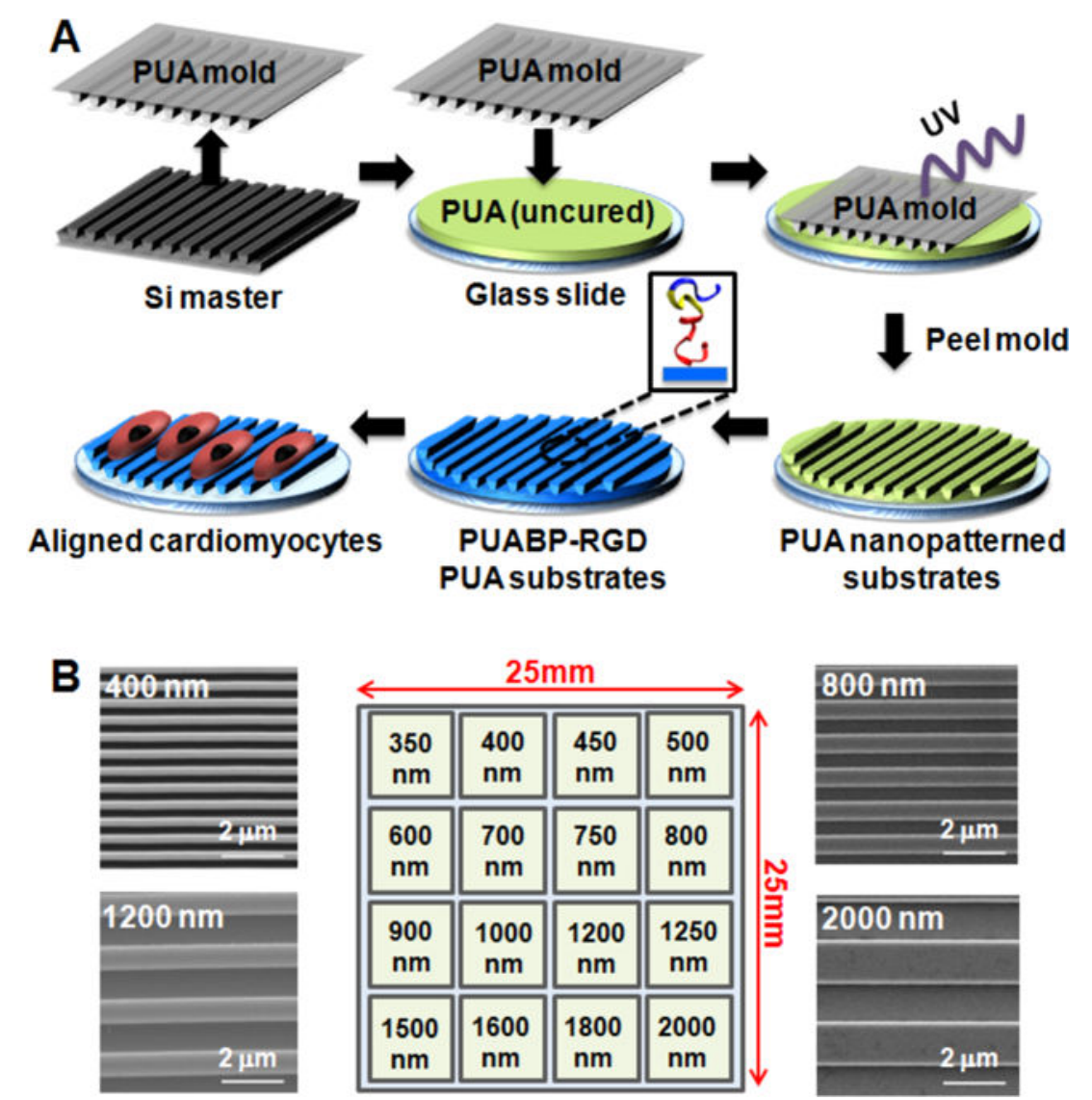

\begin{tabular}{|c|c|c|c||}
\hline \multicolumn{2}{|c|}{$25 \mathrm{~mm}$} \\
\hline \begin{tabular}{c|c|c|c|}
350 \\
$\mathrm{~nm}$
\end{tabular} & $\begin{array}{c}400 \\
\mathrm{~nm}\end{array}$ & $\begin{array}{c}450 \\
\mathrm{~nm}\end{array}$ & $\begin{array}{c}500 \\
\mathrm{~nm}\end{array}$ \\
\hline \begin{tabular}{c|c|c|c|}
600 \\
$\mathrm{~nm}$
\end{tabular} & $\begin{array}{c}700 \\
\mathrm{~nm}\end{array}$ & $\begin{array}{c}750 \\
\mathrm{~nm}\end{array}$ & $\begin{array}{c}800 \\
\mathrm{~nm}\end{array}$ \\
\hline \begin{tabular}{c|c|c|}
900 \\
$\mathrm{~nm}$
\end{tabular} & $\begin{array}{c}1000 \\
\mathrm{~nm}\end{array}$ & $\begin{array}{c}1200 \\
\mathrm{~nm}\end{array}$ & $\begin{array}{c}1250 \\
\mathrm{~nm}\end{array}$ \\
\hline \begin{tabular}{c|c|c|}
1500 \\
$\mathrm{~nm}$
\end{tabular} & $\begin{array}{c}1600 \\
\mathrm{~nm}\end{array}$ & $\begin{array}{c}1800 \\
\mathrm{~nm}\end{array}$ & $\begin{array}{c}2000 \\
\mathrm{~nm}\end{array}$ \\
\hline
\end{tabular}

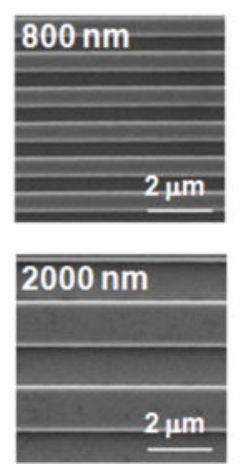

Figure 1.

Fabrication and arrangement of nanopatterned substrates on the nanogrid cell culture array. (A) Schematic illustration of UV-assisted capillary force lithography (CFL) process used to generate nanotopographically defined PUA-based cell culture substrates. (B) Diagram of nanogrid array designed for high-throughput structural maturation analyses of cultured cells. SEM images illustrate the surface dimensions of small $(400 \mu \mathrm{m})$, medium (800 and 1200 $\mu \mathrm{m})$, and large $(2000 \mu \mathrm{m})$ topographic features analyzed during this study. 
A

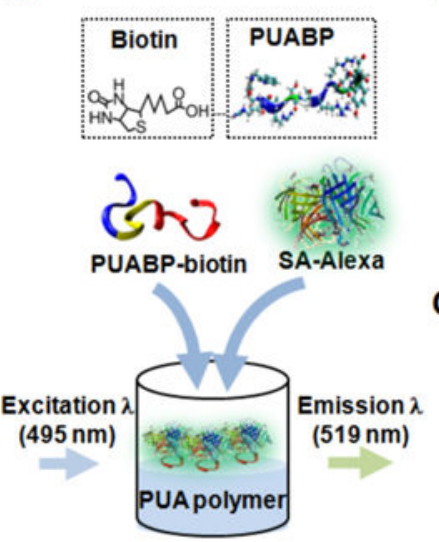

D

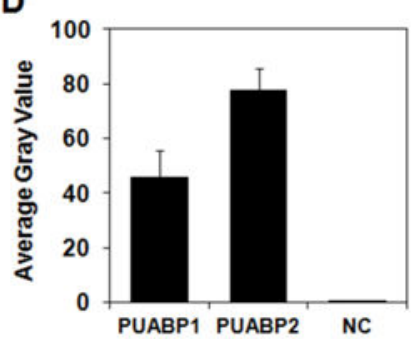

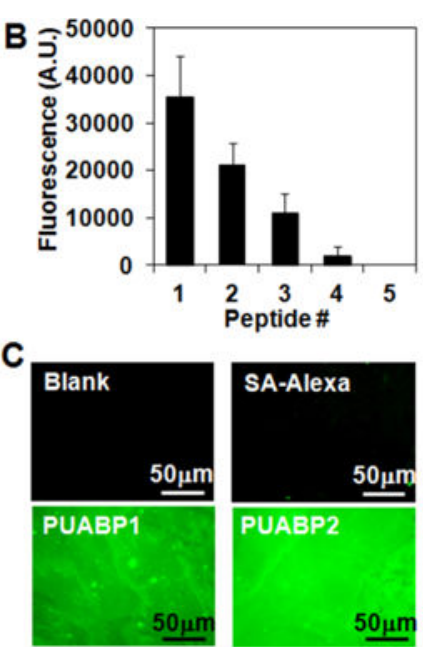

E

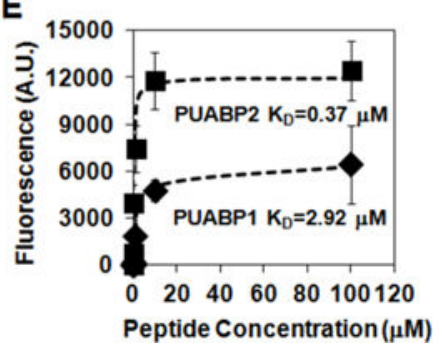

Figure 2.

Characterization of chimeric adhesion peptide affinity to PUA substrates. (A) Schematic illustration of assay to determine degree of peptide affinity for PUA substrates, in which PUABP-biotin is incubated with SA-Alexa and the resulting fluorescence emission is measured. (B) PUA binding assay for rational peptide library, each peptide was conjugated to biotin prior to use in assay. No fluorescence was detected for peptides \#6-15. $n=4$. (C, D) PUABP surface coverage characterization at $100 \mu \mathrm{M}$. Fluorescence microscopy was used to determine surface binding density compared to a blank surface (negative control; NC) and surfaces treated with SA-Alexa without PUABP-biotin. Average fluorescence intensity was measured at multiple locations on each examined substrate $(n \geq 5)$. PUABP2-biotin displayed similar surface coverage compared to PUABP1-biotin, but a higher average fluorescent intensity. Scale bar: $10 \mu \mathrm{m}$. (E) Binding curve of PUABP1 and 2 with saturation occurring for both compounds at $100 \mu \mathrm{M}$. 

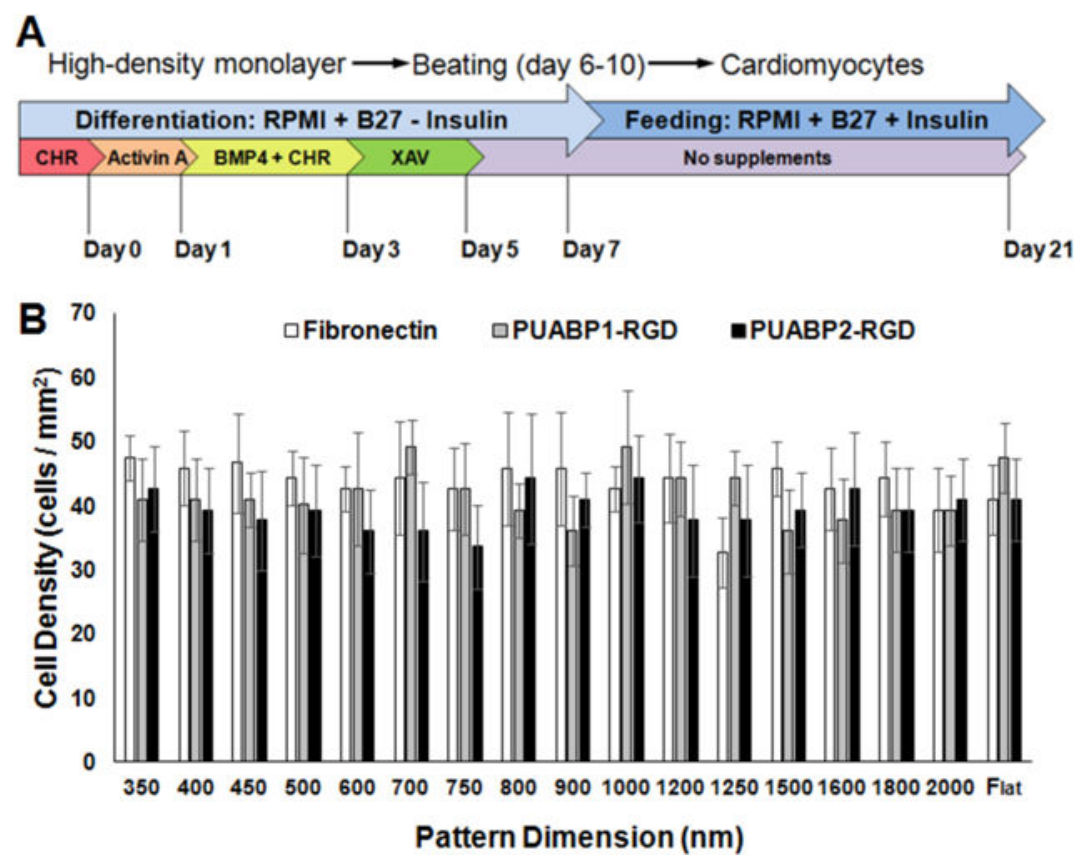

Figure 3.

Directed cardiomyocyte differentiation from hiPSCs and comparative characterization of their adhesion to functionalized PUA substrates. (A) Representative schema of protocol for differentiating hiPSCs into cardiomyocytes. Prior to Day 0, undifferentiated IMR90 human iPSCs were cultured in mouse embryonic fibroblast-conditioned medium. At Day 0, undifferentiated cells were induced with activin-A, followed by BMP-4 between Days 1 and 3. Between Days 3 and 5, the cells were treated with XAV939 (XAV), a tankyrase inhibitor. During the first week of differentiation, cells were maintained in RPMI medium with B27 (without insulin). From Day 7 onward, insulin-containing B27 was used to supplement medium. Cells were maintained on Matrigel-coated surfaces until Day 21 before being harvested using trypsin and replated onto experimental surfaces. Medium was changed every other day throughout this time course. (B) Cell adhesion analysis of IMR90 cardiomyocytes $24 \mathrm{~h}$ post replating on the nanogrid array coated with $100 \mu \mathrm{M}$ of PUABP1-RGD or PUABP2-RGD. Statistical analysis yielded no significant differences in cell adhesion among pattern dimensions and ECM coating. $p>0.05, n=20$ (distinct areas) per condition. 

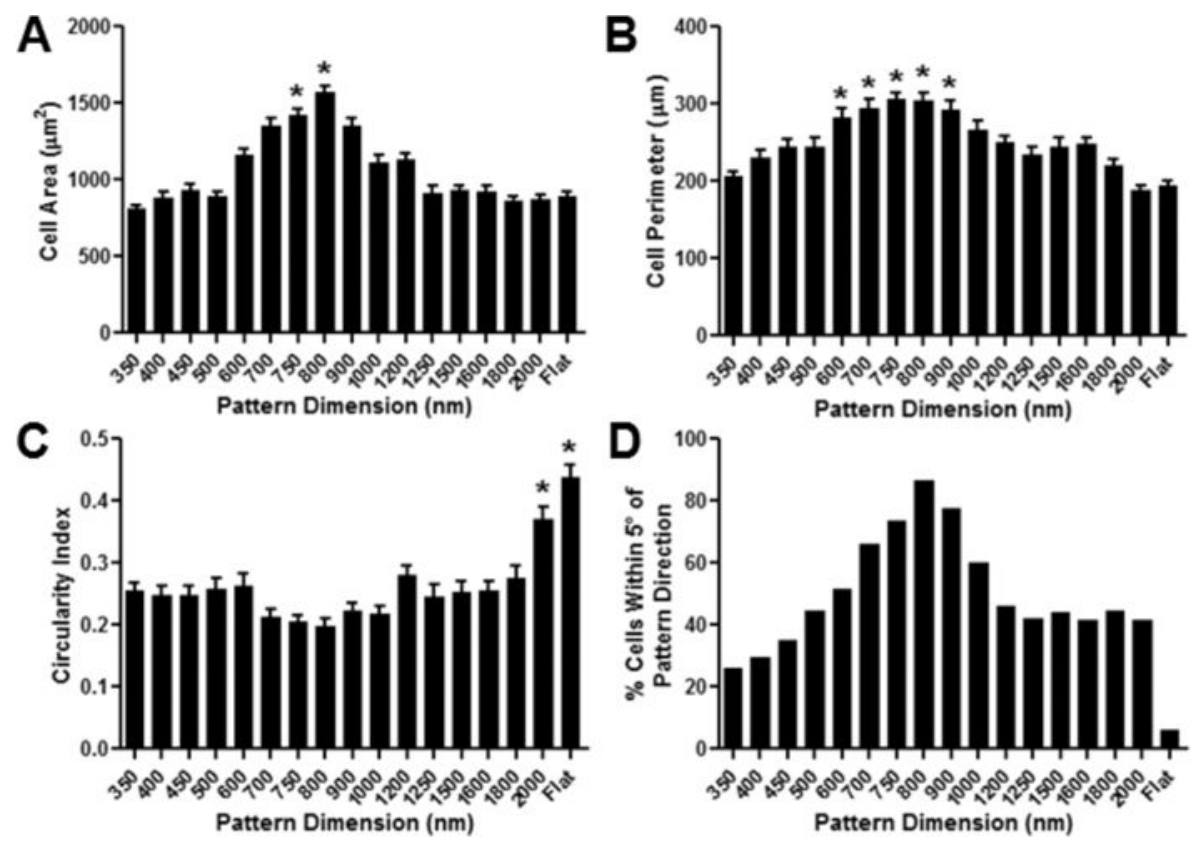

Figure 4.

Quantitative analysis of cardiomyocyte morphology in response to different nanopatterned topographies. (A) Cell area analysis of IMR90 cardiomyocytes 3 weeks post replating pattern dimensions from $4 \times 4$-island platform coated with PUABP2-RGD $(100 \mu \mathrm{M}) .{ }^{*} p<$ 0.05. (B) Cell perimeter analysis of IMR90 hiPSC-cardiomyocytes 3 weeks post plating on different nanotopographic surfaces from $4 \times 4$-island platform coated with PUABP2-RGD $(100 \mu \mathrm{M})$. Statistically significant increases in cell perimeter were observed in cells maintained on 600-900 nm groove widths when compared to all other patterned conditions and flat controls. ${ }^{*} p<0.05$. (C) Cell circularity analysis of IMR90 cardiomyocytes 3 weeks post replating pattern dimensions from $4 \times 4$-island platform coated with PUABP2-RGD $(100 \mu \mathrm{M})$. Cells on flat and $2000 \mathrm{~nm}$ patterned surfaces had significantly higher circularity indices than all other patterned conditions, indicating less anisotropic development in these conditions. ${ }^{*} p<0.05$. (D) Cell alignment analysis of IMR90 cardiomyocytes 3 weeks post replating on pattern dimensions from $4 \times 4$-island platform coated with PUABP2-RGD (100 $\mu \mathrm{M})$. Alignment was determined by the percentage of cells whose major axis was within 5 degrees of the pattern direction. Cells on $800 \mathrm{~nm}$ nanogroove width exhibited the highest degree of cell alignment compared to all other surface conditions. For all the analyses, $n=$ 60-95 cells per condition. 


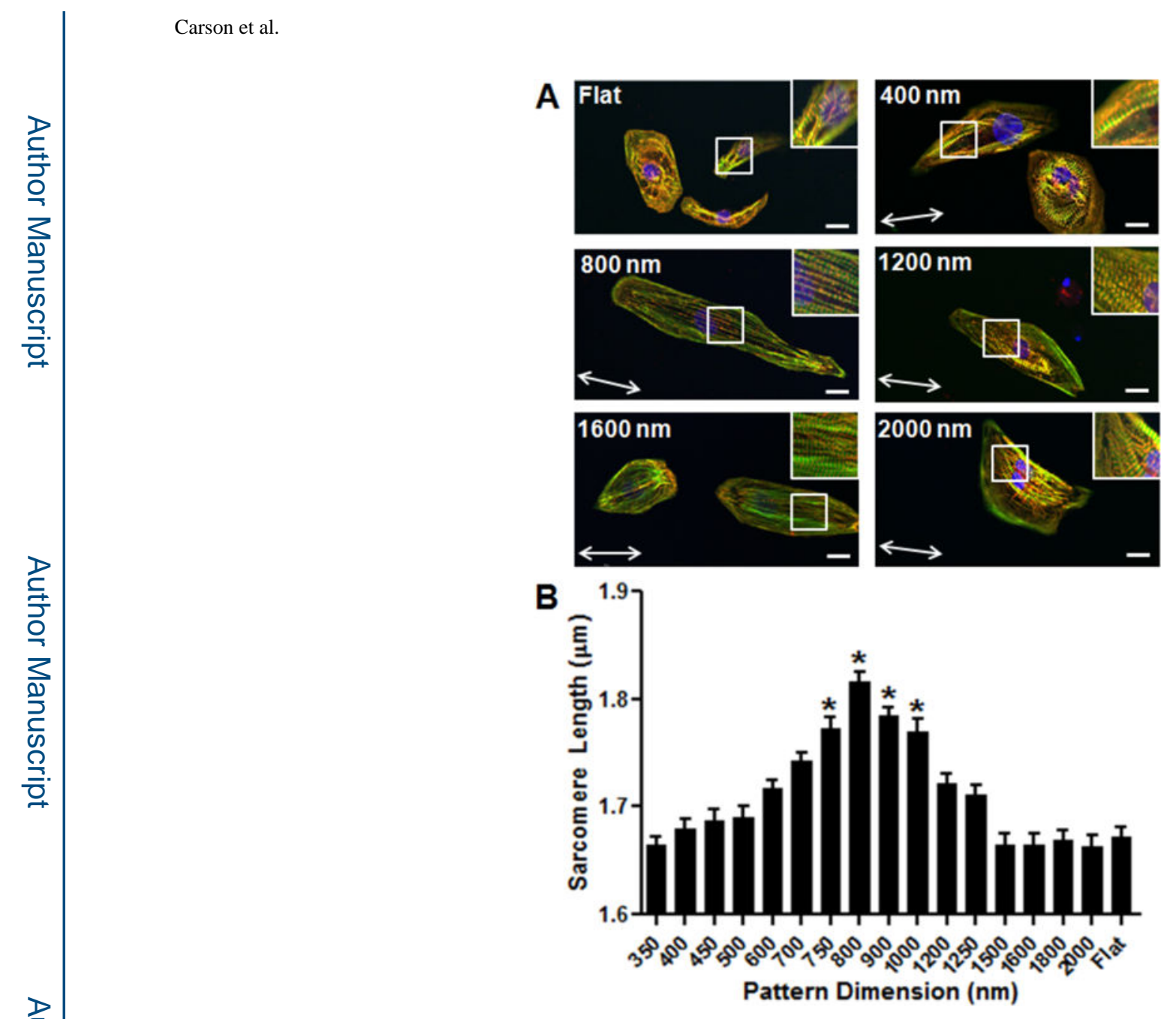

Figure 5.

Analysis of sarcomere development in hiPSC-cardiomyocytes cultured on nanotopographic substrates of different dimensions. (A) Confocal images of IMR90 cardiomyocytes with inset image fixed 3 weeks post replating on PUABP2-RGD $(100 \mu \mathrm{M})$ coated nanogrid array. Red, $a$-actinin; green, f-actin; blue, nuclei. Scale bar: $20 \mu \mathrm{m}$. (B) Sarcomere length analysis of IMR90 cardiomyocytes 3 weeks post replating on $4 \times 4$-island platform coated with 100 $\mu \mathrm{M}$ PUABP2-RGD. Statistically significant increases in sarcomere length were observed between cells on intermediate $(750-1000 \mathrm{~nm})$ groove widths. ${ }^{*} p<0.05$. 